\title{
Eylem Araştırması'nın Eğitim Alanında Kullanımı ve Önemi
}

\author{
DOI: 10.26466/opus.736788 \\ * \\ Mahmut Karatay *- Muhammed Tas ** \\ * Öğr.Gör., Munzur Üniversitesi , Tunceli M.Y.O. Tunceli/Türkiye \\ E-Posta: mahmutkaratay@munzur.edu.tr \\ ORCID: $\underline{0000-0002-4810-9000}$ \\ ** Öğretmen, MEB, Tunceli/Türkiye \\ E-Posta: $\underline{\text { muhammedtas0@hotmail.com }}$ \\ ORCID: 0000-0001-5882-5812
}

\section{Öz}

Bu çalışmada; öğretmene öğrenme metotlarını yansıtıcı değerlendirme imkanı sunarak paydaşlarla fikir alışverişinde bulunulması ve çeşitliliğgi să̆lamasında, öğrenme stratejilerine alternatif stratejiler ve program geliştirmesinde, okul kültürü ve ikliminin oluşmasında ve bir problemle karşı karşıya kalındığında bunu öz kaynakları ile çözümleyebilmesine olanak sağlayan "eylem Araştırması" tanıtılmıştır. Eğitim alanında sıklıkla kullanılan ve bilimsel araştırma yöntemlerinden biri olan eylem araştırması, katılımcilığın ön planda olduğu genel olarak nitel bir araştırmalar içerisinde kabul edilmekle birlikte, nicel araştırma yöntem ve tekniklerinin de kullanıldı̆̆ı bir araştırma türüdür. Uygulayıcıları tarafindan tasarlanan ve yaşama geçirilen eylem araştırması, özellikle öğretmenlere problem çözme ve bunu sınıf içi uygulamalara yansıtma, farklı değerlendirme teknikleri kullanarak iyileştirme ve geliştirme çalışmaları yapma konusunda yeni firsatlar sunar. Bunun için de, yönetici ve öğretmenlerin, öğrencilerin öğrenmesini iyileştirmek için sinıflarda kullanılan araştırma temelli öğretim uygulamalarını sürekli olarak araştırmak ve değerlendirmek gereksinimi içinde olmaları gerekir. Bu çalışmada ayrıca, Bir araştırma yöntemi olarak eylem araştırmasının tarihsel gelişimi, amacı ve özellikleri, aşamaları, veri toplama yöntem ve teknikleri, yararları, öğretimde kullanılması ve örnekler tartışılmıştır.

Anahtar Kelimeler: Eylem Araştırması, Eğitim, Nitel Araştırma, 
ISSN:2528-9527

E-ISSN : 2528-9535

YIl Year: 11

Cilt Volume: 17

Sayı Issue :38

Uluslararası Toplum Araştırmaları Dergisi International Journal of Society Researches

Haziran June 2021

Makalenin Geliş Tarihi Received Date: 13/05/2020

Makalenin Kabul Tarihi Accepted Date: 25/04/2021

\title{
The Use and Importance of Action Research in Education
}

*

\begin{abstract}
In this study, The "Action Research" which enables the teacher to provide reflective evaluation of learning methods, to exchange ideas with stakeholders and to provide diversity, to develop alternative strategies and programs to learning strategies, to create the school culture and climate, and to solve a problem with his own resources, has been introduced. The action research, which is one of the scientific research methods that are frequently used in the field of education, is accepted as a general qualitative research that the participation is preliminary, but it is seen that quantitative research methods and techniques are also used. The action research, designed and implemented by practitioners, offers new opportunities, especially for teachers to solve problems and reflect on it in class, using different assessment techniques to improve and improve their work. For this, administrators and teachers need to constantly research and evaluate research-based teaching practices used in classrooms to improve student learning. This study also discusses the historical development, purpose and features of the action research as a research method, its steps, data collection methods and techniques, its benefits, its use in teaching and examples.
\end{abstract}

Keywords: Action research, Education, Qualitative Research 


\section{Giriş}

Eylem Araştırması (Actıon Research), bir çalışmayı niteliksel olarak iyileştirmek için odaklanmayı ve analiz etmeyi gerektiren bir araştırma türüdür (Beyhan, 2013). Eylem Araştırması, öğretmenleri sınıf araştırmacıları haline getirerek araştırma ve uygulamayı birbirine bağlayan bir stratejik yaklaşımı kullanır. Uygulayıcıları tarafından tasarlanan ve yaşama geçirilen bu araştırma özellikle öğretmenlere daha iyi öğretim yapma ve değerlendirme için yeni fırsatlar sunar (Mills, 2017). Bu yönüyle durumsal ve yerel özellikleri dikkate alan eylem araştırması, bazı uygulamalaları neden daha iyi yaptığımızı öğrenmek ile ilgili değil, daha iyi bir öğrenme sağlamak için hangi uygulamalarımızı değiştirmemiz gerektiğine ve bu değişikliklerin hangi yönde olacağına odaklanır. Diğer bir ifadeyle eylem araştırması neyin yanlış olduğunu bulmaya çalışmaktan öte, nasıl geliştirilebileceğine yönelik bir arayışa ve anlayışa denk düşer (Eilks, 2018); Yıldırım ve Şimşek, 2016, s. 307).

Çağdaş eğitim reformu, öğretim uygulamalarını değiştirmek için esas olarak yukarıdan aşağıya ve dışarıdan yaklaşımlara odaklanmasına rağmen, günümüzde, hem eğitim politikası hem de sınıf ortamındaki yenilikler, öğretmenin sürekli mesleki gelişimi ve yaşam boyu öğrenme yaklaşımı açısından en umut verici stratejilerden biri olarak görülmektedir (Gottlieb, 2014; Biesta, ve Stengel, 2016). "Yerel bir sorunun sistematik olarak incelenmesi yoluyla eğitim uygulamalarını geliştirmesini" amaçlayan EA, tam da bu noktada, bir mesleki gelişim modeli olarak karşımıza çıkar (Lesha, 2014). Bunun için hem öğretmenler hem de yöneticilerin, öğrencilerin öğrenmesini iyileştirmek için sınıflarda kullanılan araştırma temelli öğretim uygulamalarının etkinliğini sürekli olarak araştırmak ve değerlendirmek gereksinimi içinde olmaları gerekir.

Eğitimin bilimleri alanında araştırma ve EA'nın kullanımının önemi farklı çalışmalarla (Farley-Ripple, May, Karpyn, Tilley ve McDonough, 2018; Manfra, 2019) ortaya konulmasına karşın ülkemizde özellikle sahada eğitimin niteliklerini geliştirebilmek amaciyla genelde araştırma faaliyetlerine özelde ise eylem çalışmasına yeterince yer verilmediği gözlemlerimiz arasındadır. Eğitim sistemi içindeki tüm öğrencilerin başarıya ulaşmasını sağlamak amacıyla öğrenci verilerini tutarlı ve işbirliğine dayalı bir temelde düşünmeye ve analiz etmeye teşvik etmek, karşılaşılan zorlukların üstesinden gelmebilmek için öğretmenleri ve yöneticileri bilimsel yöntem kullanmaya 
tesvik etmek, okullarda sorunların çözümüyle ilgili işbirliği, sorgulama, yansıtma ve diyalog firsatlarına dayalı kurum kültürü oluşturmak, kurumlara akademik kimlik, öğretmenlere profesyonellik ve özerklik kazandırmak amacıyla, bu çalışmada; eğitim alanı için etkinliği kantlarla ortaya konulmuş bir araştırma türü olan eylem araştırmasının yeniden sentezlenerek gözden geçirilmesinin yararlı olacağı düşünülmektedir.

\section{Eylem Araştırmasına İlişkin Tanımlar}

Eylem araştırmalarının çok farklı tanımları bulunmaktadır. Lewin (1947), eylem araştırmasını, "keşfedilecek noktaların araştırmasını kapsayan bir planlama, eyleme geçme ve eylemin sonuçlan hakkında bulgular elde etme" şeklinde üç aşamalı sarmal bir süreç olduğunu ortaya koyarken, Corey (1953) eylem araştırmasını, "uygulamacıların sorunların bilimsel olarak çözmelerinde rehberlik, dikizleme ve değerlendirme girişimlerinden oluşan bir süreç" olduğunu ileri sürmüştür. Glickman (1992) ise eylem araştırmasını okul dizeyinde ele alarak, "meslektaşların öğretimi iyileştirme etkinliklerinin sonucu ortaya çıkan bir süreç" olarak tanımlamıştır (Akt. Aydın, 2016, s. 249).

Costello (2007)'ya göre, eylem araştırması "kişilerin kendi mesleki eylemleri hakkında araştırma yapmaları ve değişim için eyleme geçmeleri temelinde gerçekleşen sistematik bir müdahale süreci"dir. Kemmis (1988) 'e göre ise eylem araştırması, "sosyal durumlardaki katılımcıların çeşitli amaçlar ile yürüttükleri ve kendilerini yansıtıcı araştırma" şeklidir. Johnson (2014) eylem araştırmasını, "gerçek sınıf ortamında, öğretimin niteliğini anlama ve geliştirmeye yönelik bir süreç; önceden planlanmış, düzenlenmiş ve diğer ilgili kişilerle paylaşlabilen bir araştırma türü" olarak tanımlarken, Sagor (2003), eylem araştırmasını, "sürecin içindeki kişilerce yine kendi çalışma koşullarının iyileştirilmesi amacıyla gerçekleştirilen sistemli çalışmalar bütünü" olarak tanımlamıştır.

Watts (1985)'a göre eylem araştırması, “katılımcıların araştırma tekniklerini kullanarak kendi eğitim uygulamalarını sistematik olarak dikkatle gözden geçirme sürecidir" (Akt. Ferrance, 2000, s. 7). Eylem araştırmasını, öğretmenlerin (ya da eğitim ortamındaki diğer bireylerin) belirli eğitim ortamlarının nasıl işledikleri, nasıl öğrettikleri ve öğrencilerin ne kadar iyi öğrendikleri ile ilgili bilgileri toplamak ve daha sonra geliştirmek için yapılan sistematik araştırma olarak açıklayan, Mills (2003), eylem araştırması yöntemi ile okul 
veya sınıf ortamında bulunan uygulayıclar eğitsel etkinlikler geliştirirken, bu etkinliklerin uygulanması esnasında yaşanan önemli sorunları nasıl çözeceklerini anlamalarına da katkı sağladığını belirmektedir.

O'Brien (1998), eylem araştırmasının, asıl odak noktası gerçek problemleri çözmek olduğundan, deneysel çalışmalardan ziyade, gerçek durumlarda kullanıldığını belirtirken, sosyal bilimciler tarafından ön araştırma veya pilot araştırmalar için, özellikle durumun kesin bir araştırma sorusunu çerçevelemek için çok belirsiz olduğu durumlarda kullanılabileceğini savunur. Eylem araştırmasını, "yaparak öğrenme" olarak tanımlasa da, bu yöntemi uygulayan kişinin, kuramları sorgularken kendi inanç ve düşünce yapısının etkisinde kalmasından dolayı, sadece uygulama ağırlıklı basit bir araştırma yöntemi olmadığı söyleyerek, konuya hakim olan uygulayıcının, bilinçli bir şekilde farklı farklı uygulamalar denediğini savunmaktadır.

Yıldırım ve Şimşek (2016, s. 307) eylem araştırmasını; uygulayıcılar olarak yönetici, öğretmen ve diğer çalışanların, kendisinin ya da başka bir araştırmacı ile birlikte, sorunların ortaya çıkarılmasına veya ortaya çıkmış sorunların anlaşılması ve çözülmesine yönelik sistematik olarak veri toplama ve analiz süreçlerini içeren bir araştırma yaklaşımı olarak tanımlar. Kuzu (2009) ise; öğretmen veya akademisyenlerin aktif olarak araştırmacı rolü üstlenerek kullandıkları bu yöntemin, eğitiminin farklı konularında bilgi elde etme ve çeşitli uygulamalar geliştirme amacıyla kullanabildiğine değinmiştir. Köklü (2001, s. 36-38)'ye göre ise, öğretmenlere araştırma yöntemleri ve uygulamaları konusunda "bilgi ve yeti kazanma" olanağı vermenin yanı sıra, değişim olanağı ve seçenek sunma konusunda daha bilinçli olmalarını sağlayan, kendi uygulamaları konusunda daha eleştirel ve titiz olabilmelerine fırsat veren ve öğretme süreçlerine bütünlüklü yaklaşmalarını gerektiren bir süreç olarak tanımlanabilir. Bu yönüyle EA'nın diğer disiplinlerde kullanılan araştırmalardan farkı, sorunun tespitiyle birlikte uygulamaların değerlendirilmesine olanak vermesi yanında müdahale odaklı olmasıdır. Bu nedenle EA sadece veri işlemenin ön planda olduğu bir araştırma faaliyeti olarak görülmemelidir.

\section{Eylem Araştırmasının Tarihsel Gelişimi}

Eylem araştırmaları uzunca bir geçmişe sahiptir. Wallace (1987, Akt. Ekiz, 2009, 180), eylem araştırmalarının, 1945 yılında yerli Amerikan halkının 
tarımsal faaliyetlerini geliştirmek amacıyla yapılan çalışmaları tanımlanmak amacıyla ilk kez Collier tarafından kullanıldığını savunurken, Reason (2001) ise Avrupa ve Amerika'da savaş sırasında ortaya çıkan birtakım problemlere çözüm bulabilmek amacıyla sosyal bilimciler tarafından ortaya atılmış olduğunu savunmaktadır. Eylem araştırmasının tarihsel gelişimi konusunda ortak bir görüş bulunmamaktadır. Alan yazının son yüzyıllık geçmişi incelendiğinde, bu araştırma yönteminin 19. yüzyıldaki “Eğitimde Bilim Hareketi'ne kadar uzandığını öne süren araştırmacılar olsa da eylem araştırmasının ilk kez Kurt Lewin'in çalışmaları ile başladığı ve kavramsallaştııldı ğı genel kabul görmektedir (Masters, 1995). Kemmis (1998) ise "grup dinamiği", "sosyodrama" ve "psiko-drama"nın yaratıcısı olan J.L. Moreno'un eylem araştırması fikrini Kurt Lewin'den önce geliştirdiğini öne sürmektedir.

Eylem araştırmasının ilk ortaya çıkışyla ilgili farklı referanslar olmasına rağmen, gelişim sürecinin genel olarak şöyle bir seyir izlediği söylenebilir;

John Dewey (1929), "öğretmenlerin en önemli rollerinden birinin araştırma yoluyla pedagojik sorunları incelemek" olduğunu belirterek, okulun başarı ve başarısızlıklarında en önemli araştırmacılar olarak öğretmenleri görmüş ve çalışmalarıyla eğitimde eylem araştırmasının temellerini atmıştır (Akt. Kincheloe, 1993, s. 16).

Kurt Lewin 1946 yılında bir makalesinde işbirlikçi problem çözmenin geliştirilmesi üzerine odaklanarak eylem araştırması stratejilerine değinmiştir . Bu stratejilerde, bireysel problem çözme yerine işbirliğine dayalı problem çözmenin önemli olduğuna vurgu yapmış ve grup çalışmalarının eylem araştırması sürecinin bir parçası olduğunu belirtmiştir. Grup tartışmalarındaki etkileşimli süreçlerin, bireylerin davranış ve eylemlerinin değiştiğine inanan Lewin'e göre eylem araştırması; "gerçeklerin bulunmasına yönelik bir planlama", "harekete geçme" ve "eylemin sonuçlarına ilişkin gerçekleri ortaya çıkarma" olarak üç dairesel aşamada gerçekleşmektedir (Lewin, 1946; Masters, 1995).

Stephen Corey (1953), eylem araştırması araştırma yöntemini, eğitsel sorunların çözümünde, sistematik olarak uygulayan ilk kişidir. Corey, eğitimde esaslı değişikliklerin olmasının, eğitim yöneticilerinin ve öğretmenlerin eğitime doğrudan katılımlarıyla mümkün olacağını belirtmiş, yönetici, denetici, öğretmen, öğrencilerin ilerlemelerinin ve çağa ayak uydurabilmelerinin gereği olarak sürekli bir araştırma ve inceleme içerisinde olmaları gerektiğiyle ilgili uyarılarda bulunmuştur (Glanz, 1999). 
1950'li yıllarda eylem araştırmalarının bilimsel olmadığıyla ilgili yapılan eleştirilerin yanı sıra, öğretmen ve araştırmacıların birlikte çalışması gerektiği savunulmuştur. İlerleyen yıllarda, pozitif bilimlere artan ilgiyle doğrultusunda, araştırma yöntemi olarak deneysel yöntemin norm haline gelmesiyle birlikte eylem araştırması çalışmalarına olan ilgi azalmıştır (Ferrance, 2000, s. 7-8). 1960'11 yıllarda azalan ilgi yanında, eylem araştırmaları ciddi eleştirilere maruz kalmıştır. Eleştiriler genel olarak; araştırmalarda yapılan planlamalardaki yetersizlikler, problemler tanımlanırken ilgili faktörlerin göz ardı edilmesi, araştırma sonuçlarının eğitim alanına katkısının çok az olması, çalışmaların daha çok örnek olaylara dayandırıldığı ve evreni temsil etmediği gibi düşünceler etrafında yoğunlaşmıştır (Glanz,1999).

1970'li yıllara gelindiğinde, federal yönetimlerce desteklenen ve kurumsal düzeyde kalan bu araştırmaların uygulamada karşılığının olmadığının düşünülmesine ve eğitim uygulayıcıları tarafından, sorunlarının çözümünde, bilimsel araştırma yöntemleri ile birlikte eylem araştırması yönteminin de eğitimde uygulanabilirliğinin sorgulanmaya başlanmasına rağmen, eylem araştırmasına olan ilgi tekrar yükselmeye başlamıştır (Ferrance, 2000, s. 8). Özellikle, 1970'li yılların sonlarında Lawrence Stenhouse ve John Elliot'un çalışmaları eylem araştırmasının tekrar gündeme gelmesinde etkili olmuştur. 1970-80'li yıllarda, eylem araştırması geniş bir alana yayılarak, eğitimde yoğun olarak kullanılmaya başlamıştır. Lawrence Stenhouse gibi bazı eğitimciler, Lewin'in görüşlerini geliştirerek eylem araştırmasını, eğitimin önemli konularında kullanılmasını sağlamışlardır. Eylem araştırmalarının, öğretmenlerin mesleki gelişimlerini sağlamak amacıyla kullanıldığı bu yıllarda, eğitimcilerin, bu araştırma yönteminden aktif bir biçimde yararlandığı görülmektedir. 1980'li yıllara kadar, üniversitelerde ve bölgesel merkezlerde düzenlenen kurslarda verilen mesleki eğitimler akademi merkezli olmaktan çıkıp, öğretmen merkezli eğitim araştırmalarına dönmüştür (McNiff, 1988). "Araştırmacı olarak öğretmen" terimini ilk kullanan İngiliz eğitimci Lawrence Stenhouse (1975), öğretmenlerin de araştırmacı olabileceğini ve kendi uygulamalarını eylem araştırmaları yoluyla geliştirebileceklerini ileri sürmüştür. Bu görüşler sonraki yıllarda, araştırma ve uygulamanın farklı olmadığı iç içe olduğu, birbirini desteklediğini ifade eden, Eliot ve Adelman gibi araştırmacılar tarafından geliştirilmiş̧ir (Akt. Ekiz, 2009, 182).

Devam eden yıllarda, çağdaş eğitimde devam eden reform çabalarıyla birlite, bilimsel veriler ve eylem araştırmaları yoluyla uygulamayı 
değiştirmeye yönelik başarılı çabalar, öğretmenleri eğitim araştırmalarına aktif katılımcılar olarak dahil edilmesinin önemini giderek daha fazla ortaya koymuştur. Bu süreçte, öğretim uygulamasının eğitim reformuna yönelik yukarıdan aşağıya, herkese uyan tek tip yaklaşımlardan çok az etkilendiği, dolayısyla sorunların yerinden çözülmesi açısından bilimsel bir yaklaşım sunan eylem araştırmasının önemini gösterilmiştir (Manfra, 2019). Günümüzde Eylem araştırması eğitimin birçok alannda kullanılmaktadır.

Elliot (1991, s. 49)’a göre "eğitimde eylem araştırmasının temel amac1, bilgi üretmekten çok uygulamayı geliştirmektir". Eylem araştırmasının kuram ile uygulama arasındaki sorunları ortadan kaldırdığını, kuram ile uygulama arasındaki ilişkinin öğretmenler için uygulamada sorun yarattı̆̆ını savunmaktadır. Öğretmenlerin, teoriyi statü ve mesleki bilgilerine yönelen bir tehdit unsuru olarak gördükleri, akademik topluluk tarafından geliştirilen teorilerin mesleki uzmanlık ve deneyimlerinden uzak olduğu düşüncesi taşıdıklarını ileri sürmektedir. Ayrıca, öğretmenlerin, teorinin ortaya koyduğu "ideal uygulama modellerine" ulaşamadıkları için başarısız olarak görüldüklerini savunmuştur.

\section{Eğitim Alanında Eylem Araştırmasının Amacı ve Özellikleri}

Eğitim alanında, uygulamalar sonrası ortaya çıkan gerçeklerin anlamlandırılması ve sistematik bir şekilde değiştirerek geliştirilmesini temel amaç edinen eylem araştırması (Kuzu, 2009), okula dayalı "program geliştirme", "mesleki gelişme", "sistem planlaması", "okulu yeniden yapılandırma" ve bir "değerlendirme" aracı olarak kullanılmaktadır" (Ferrance, 2000, s. 26). Elliot (1991, s. 49), hemen tüm alanlarda farklı nedenlerle ortaya çıkan sorunların çözümü için kullanılabilecek bu araştırma türünü, uygulayıcıların kendi uygulamaları üzerinden çözüm üretmek üzerine kurulu bir süreç olarak açıklarken, Köklü (2001, s. 35), benzer bir görüşle, eylem araştırmasının, araştırmalara rehberlik edecek teoriler geliştirmeyi amaçladığını ve katılımcıların üzerinde çalışılan duruma ilişkin derinlemesine yaptığı kritik ve pratik tecrübelerine dayandığını ifade etmiştir.

Genel olarak alanyazın incelendiğinde eylem araştırmalarının genel özellikleri şöyle sıralanmıştır; 
Eylem araştırmalarn sistematiktir: Eylem araştırması yöntemsel ve planlı bir gözlem olduğundan, veri toplama araçları, yöntemi ve süresi sistematik bir yaklaşım belirlenmelidir.

Araştırmaya bir yantla başlanmaz: Araştırmacı önyargısız olarak başlayacağı gözlemde, problemin veya durumun tespiti ve çözümüne yönelik araştırma sorularına odaklanır. Cevapların ne olduğu süreç sonunda netlik kazanir.

Bir eylem araştırması karmaşık veya ayrıntılı olmak zorunda değildir: İyi düzenlenmiş bir eylem araştırması çok fazla ayrıntıya takılmadan gerekli bilgilerin aktarıldığı bir yapıya sahip olmalıdır. Aksi takdirde okuyucu tarafından okunmak istenmez veya anlaşılmaz.

Veri toplanmaya başlanmadan önce araştırmanın dikkatlice planlanması gerekir: Veri toplamaya başlamadan önce bir takım plan ve ön hazırlıkların yapılması, araştırmanın sağlıklı yürüyebilmesi için çok önemlidir. Çalışma esnasında bir takım değişiklikler yapma fırsatı sunsa da sistematik bir sorgulama gerektirdiği için dikkatli planlanmalıdır.

Araştırma projesinin uzunluğu değişebilir: Araştırma sorusu, süresi, ortam ve veri toplama araçlarına göre çalışmanın süresi farklılık gösterebilir. İki aydan bir eğitim öğretim yılına kadar süren çalışmalar yapılabilir.

Gözlemler düzenli olmalıdır: Gözlemler süreç içerisinde düzenli olarak yapılmalı ve önceden planlanmış bir programla yürütülmelidir. Alınan gözlem notları gözlem süresine göre farklı uzunluklarda olabilir.

Eylem araştırma projeleri basit olabileceği gibi ayrntılı da olabilir ve sonuçlar resmi çalışmalar için de kullanılabilir: Bazı araştırma projeleri kısa ve basitken bazıları ayrıntılı ve karmaşıtır. Bu özelliklerine göre yazılan raporlar resmi çalışmalar için de kullanılabilir.

Eylem araştırmaları kuramın içine gömülï olabilir: Soruları, bulguları ve sonuçları var olan bir kuramla ilişkilendirmek, araştırmanızı bir başka 
araştırma raporunun sonuçları ile nasıl ilişkilendirdiğinizi ortaya koymanıza yardımc olabilir.

Eylem araştırması nicel araştırma türleri içinde yer almaz: Eylem araştırmalarında amaç anlamaktır. Herhangi bir ispat yapılması zorunluluğu olmadığından bir başka çalışma ile karşılaştırmanız veya deney kontrol gruplu bir çalışma yapmanız gerekmemektedir.

Sayısal sonuçlara dayanan eylem araştırması projelerinin bulguları sınırlıdır: Eylem araştırmalarında nicel yöntemler kullanılmasına rağmen, araştırma sonuçlarını yorumlamada geniş kitlelere genelleme yapılırken dikkatli olunmalıdır. Bunun nedeni küçük gruplarla çalışılması ve kontrol edilemeyen veya hesaba katılmayan bir takım değişkenlerin de ortamda yer almasıdir (Sage Publication, 2020; Tezcan, Ada ve Baysal, 2016; Burns, 2019)

Bu özellikleri çoğaltmak mümkündür. Özellikler bağlamında değerlendirilirse eylem araştırması yaparken, ön yargılardan uzak olunması, elde edilecek verilerin sistematik olarak yapılan gözlemlere dayalı olması, herhangi bir genelleme ve ispat çabası içerisine girilmemesi ve okuyucuların anlayacağı sade bir dille yazılması, araştırmanın niteliğini arttırarak, gelişmelere ışık tutacaktır.

Eylem araştırmasına yönelik yapılan modellemelere bakıldığında; Stringir Modeli, Mills Modeli ve Wallece Modeli gibi moddelerin olduğu görülmektedir (Nasrollahi, Krish ve Noor, 2012). Bu modellerde genel olarak; planla, uygula, tekrar planla şeklinde doğrusal olmayan bir düzlemde, döngüsel olarak kurgulandığı görülmektedir. Bu, eylem araştırmasının, gelişime dayalı özelliğinden kaynaklanmaktadır.

\section{Eylem Araştırmasının Aşamaları}

Costello'ya (2007) göre, eylem araştırmasının türü ne olursa olsun, yöntemin gerektirdiği genel çerçeve benzerdir ve eylem araştırması modeli: "Planlama", "eylemde bulunma", "izleme/ gözlemleme" ve "yansitma/geribildirime göre uyarlama" adımlarından oluşmaktadır. Bu adımlar döngüsel bir düzlemde birbirini etkilemekte ve istenen sonuçların elde edilmesine kadar bu süreç devam etmektedir. Tüm bu döngünün içinde öğretmen etkin bir şekilde rol oynamaktadir. 


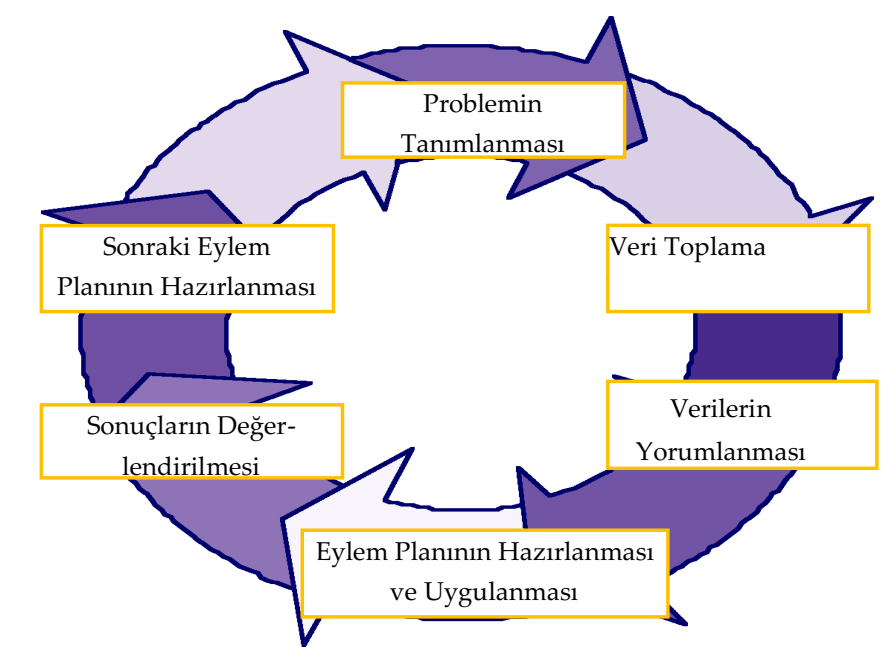

Şekil 1. Eylem Araştırmalarının Aşamaları. Kaynak: Ferrance, E. (2000).

Bassey (1988) eylem araştırmasını "üç anahtar soru"ya dayalı "sekiz aşama"ya ayırmıştır (Akt. Köklü, 2001, s. 39-41).

Bassey 'in üç anahtar soru ve sekiz aşamalı eylem araştırmaları Şekil 2'deki gibi modellenebilir:

\section{Eylem Araştırmasında Veri Toplama Yöntem ve Teknikleri}

Eylem araştırması nitel bir araştırma olarak kabul edilmekle birlikte; veriler, hem nitel hem nicel yöntemlerle elde edilebilir (Aksoy, 2003). Eylem araştırılması mikro düzeyde bir sorunla ilgilenir ve araştırmacının tecrübe ve görüşleri veri olarak kabul edilir (Beyhan, 2013). Makul geçerliliği ve güvenilirliği sağlamak için, eylem araştırmacıları herhangi bir tek veri kaynağına güvenmekten kaçınmalıdır. Çoğu araştırmacı, bulgularının geçerliliğini ve güvenilirliğini arttırmak için üçgenleme denen bir süreç kullanır. Temel olarak, üçgenleme, kişinin sorularını yanıtlamak için birden fazla bağımsız veri kaynağı kullanmak anlamına gelir. Üçgenleme, bir kutunun içinde bulunan bir nesnenin, kutunun kenarlarına kesilmiş çeşitli pencerelerden bakılarak incelenmesi gibidir. Birden fazla "pencere" ile gözlem yapmak, tek bir araştırmacının, çeşitli lensler aracılığıyla görülenleri karşılaştırıp karşılaştırmasına yardimcı olur (Sagor, 2003). 


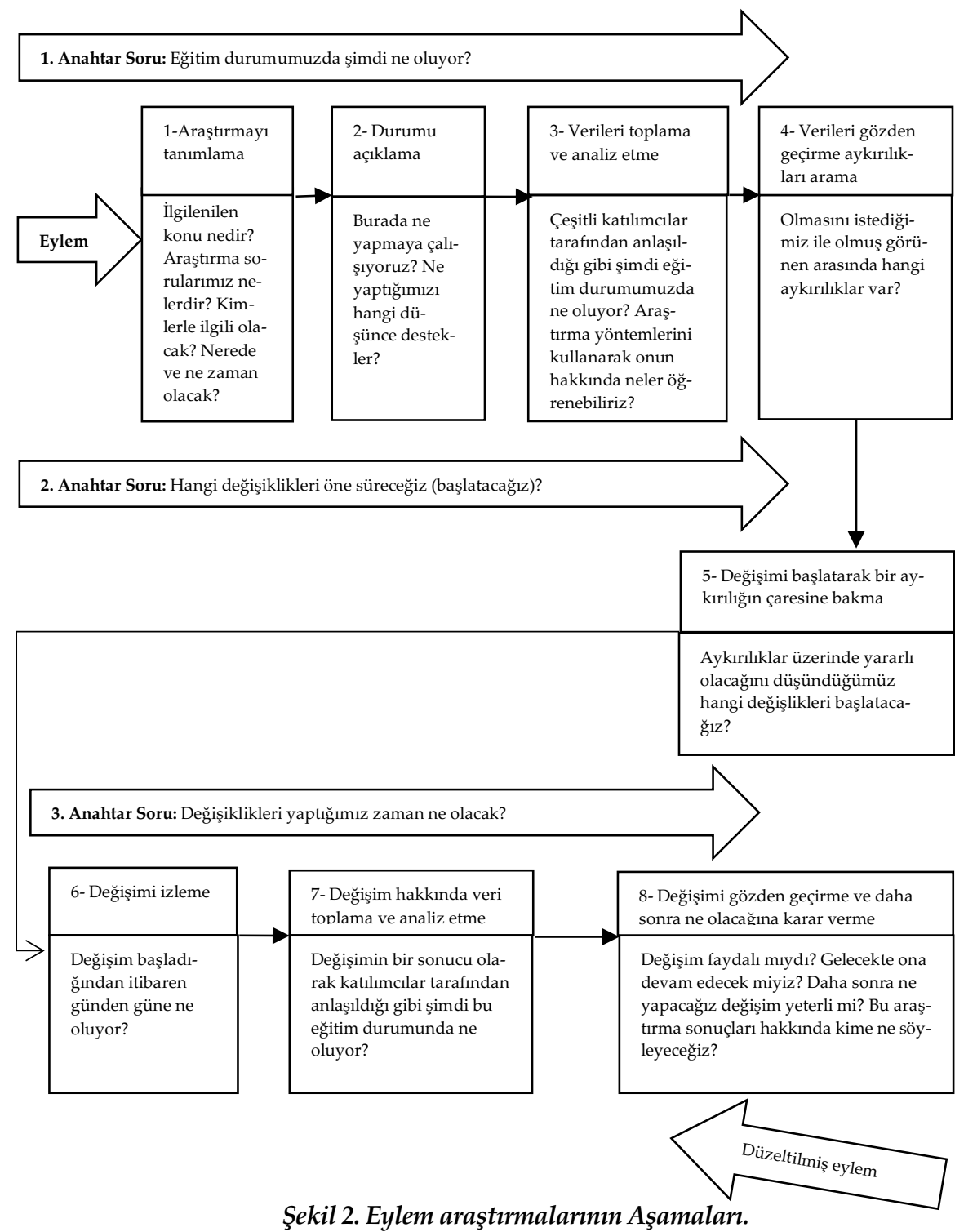

Kaynak: Bassey (1988: Akt. Köklü, 2001, 40)'den uyarlanmıştır.

Ferrance (2000), eylem araştırmasında: Görüşmeler, ses kasetleri, bireysel dosyalar, anekdot notları, fotoğraflar, anketler, öğrenci çalışma örnekleri, testler, rapor kartları, yarı yapılandırılmış testler vb. yöntemlerle veri 
toplanabileceğini ifade etmiştir. Eylem araştırılmasında veri toplanırken; deneyime, sorgulamaya ve incelemeye dayalı olarak veri toplanabilir. Sorgulamaya dayalı teknikler daha çok; görüşmeler, anketler, kontrol listeleri öz değerlendirme formları gibi veri toplama araçlarını içerir. İncelemeye dayalı teknikler; ses ve video kayıtları, internet kayıtları, günlükler gibi veri toplama araçlarını içerir. Deneyime dayalı tekniklerde ise, gözlem, katılım, saha notları gibi veri toplama araçlarını içerir (Hendricks, 2016).

Eylem araştırılmasından elde edilen verilerin çözümlenmesinde en sık kullanılan yöntemler; betimsel, içerik ve tümevarım çözümlemesidir (Kuzu, 2009). Eylem araştırmalarında nicel yöntemlerden yararlanırken, genellemelerden kaçınılmalıdır. Eylem araştırmalarında bir şeyin ispat edilmesi, deney ve kontrol gruplarının olması söz konusu değildir. Çünkü eylem araştırılmasında veri toplamanın amacı, çalışılan konuya bir dizi fotoğraf sunulması ve başkaları tarafından gözlemlenebilir olmasıdır (Tüzel, 2012). Bu noktada, eylem araştırması var olan bir problemin anlaşılmasını sağlayan sistematik incelemelerdir.

\section{Eylem Araştırılmasının Yararları}

Eylem araştırması, birçok disiplinde kullanılmasına rağmen özellikle eğitim alanına önemli katkı sağlamıştır. Eylem araştırmasının, öğretmelerin gelişiminde ve dolayısıyla öğrencinin öğrenmesinin gelişiminin sağlanmasında büyük bir payı vardır. Elliot(1991)'e göre, eğitim alanındaki uygulamaların araştırma yoluyla geliştirilmesine, öğretmenin mesleki gelişimini, program geliştirme ve değerlendirmeyi bir araya getirerek önemli katkılar yaptığını belirtmiştir. Eylem araştırmasının kullanımıyla başta öğretmenler olmak üzere, kendini tanıma ve geliştirme açısından fırsat oluşturur (Beyhan, 2013).

Aksoy (2003)'a göre eylem araştırması, bilginin paylaşmasında, farkındalık gelişiminde, okul ikliminin artırılmasında, sorun çözümüne farklı bakış açısı getirerek sorgulama odaklı bakış açısının oluşmasını sağlar. Tüzel (2012), eylem araştırmasının uygulamaya dönük olması ve sorunun tespit edilmesi kadar sorunun çözümüne odaklanması ve öğretimin kalitesinin artırılması amacıyla gerçek okul ve sinıflarda araştırma yapma süreci olarak görürken; Hopkins (1993), eylem araştırmasını, öğretmenler için döngüsel geri bildirimlerle öğretmenin eksik olduğu ya da firsat oluşturmak istediği alanla ilgili öz değerlendirme imkanı sağlayarak gelişimine ve bunu 
yaparken de karşılıklı görüş alışverişinde bulunarak örgüt içerisinde iletişimi güçlendirmeyi ve öğretmenin kendisini bir aynada görüyormuş gibi bakmasına imkan tanıyan bir yaklaşım olarak görmektedir.

Eylem araştırmasının en çok kullanıldı ğı yerlerden biri de öğretmen yetiştirme süreçleridir. EA'nın öğretmen yetiştirmede önemi, öğretmen adaylarına yeterli öğrenme yaşantısı sunarak yansıtıcı öğretmen olarak yetişmelerini sağlayacak fırsat ve olanaklar oluşturmk ve öğretmen adaylarına, öğretme deneyimleri kazandırmaktır (Kuzu, 2009).

O’Brien (1998), eylem araştırmasının sadece araştırma yöntemi olmad1ğını aynı zamanda eylem araştırması yöntemini uygulayan kişinin, bilinçli bir şekilde farklı uygulamalar da denediğini öne sürmektedir. Uzuner (2005) ise öğretmenler ve diğer paydaşlar eylem araştırması yaparak; sistematik, işbirlikçi ve yansıtıcı sorgulamalarda bulunarak problem çözmeyi sağlar. Bu yaklaşım öğretmenlerin iyileştirme amacıyla döngüsel eylemlerde bulunmasinı, öğretmenler kadar öğrencilerinde öğrenme sürecine daha fazla odaklanmasını sağlar.

\section{Eylem Araştırmasının Öğretimde Kullanılma Aşamalanı}

Okullarda günlük problemlere çözüm bulmak amacıyla bilimsel bir yaklaşım olarak kullanılan eylem araştırmalarında, Glickman(2002)'a göre uyulması gereken temel aşamalar şunlardır;

- Problemin tanımlanması ve problemle ilgili veri toplanması,

- Planlama ve uygulama aşaması

- Değerlendirme ve yansıtma aşaması

Eylem araştırmasının öğretimde kullanılması, daha çok öğretmenlerin ya da paydaşların düşüncelerini aktarması, derinleştirmesi konuyla ilgili gelişimi sağlayarak geliştirilen düşünceleri uygulamaya koymak için başvurulacak bir yöntem olarak düşünülebilir (Aydın, 2016). Eylem araştırması, öğretmen eğitiminin bir parçasıdır, bir sorunu bir konuyu ya da bir bölgeyi ele alarak inceler öğretmenin kendisini geliştirmesi öğrencinin de gelişiminin geliştirilmesidir, Ayrıca istekli olmayan öğretmenlere de koçluk yapar (Tezcan, Ada, \& Baysal, 2016). Bunların dışında yöneticiler ya da veli- çevrenin de eylem araştırmasının bir parçası olabilirler. Yöneticiler öğretmenlerle iletişimi güçlendirerek örgütsel ilişkilerini geliştirir ve öğretmenlerin kendilerini 
geliştirmesi için bir fırsat verir; veli- çevre unsurları da bölgesel bir sorunun çözümünde yardımcı olabilir.

Yiğit(2016)'e göre; eylem araştırmasi:

- Okul yaşamının idari anlamda geliştirilmesinde,

- Öğretmenlerin kişisel mesleki gelişiminin sağlanmasında,

- Geleneksel yöntemlerin yerine bilimsel yöntemlerin kullanılmak istendiğinde

- Öğrencinin anlama düzeyinin tespitinde ve geliştirilmesinde,

- Bir konu hakkında farklı fikirler geliştirilmek istendiğinde kullanılabilir.

Kısaca; eylem araştırması okullarda her öğretim kademesinde uygulanabilir. Öğretmenelere ve öğrencilere, farklı pencerelerden bakma firsatı sunar ve öğretim yöntemini geliştirir. Öğretmenlerin ve öğrencilerin sınıftaki veya okuldaki uygulamaları yapmak için farklı yöntemler kullanma olanağı bulur. Böylece, öğretmenin kendisini geliştirmesi öğrencilerin de öğrenmesine yansıyacaktır. Öğretmen bu konuda kendisini yetkilendirecek ve kendisinin güçlü ve zayıf yönlerinin farkında olabilecektir.

\section{Eylem Araştırmasıyla İlgili Örnekler}

Bir öğretmen öğretimdeki eksikliklerinin farkında olup öğretimini geliştirmek ve gerekli paydaşlardan yardım isteyebilir. Ya da bir öğrenciyle ilgili ya da okulunun geneliyle ilgili sorun yaşamış olabilir. Bu durumda öğretmen, ilgili durumla ilgili veriler toplar, eylem planı belirleyerek uygular ve öğrencilerindeki değişikleri gözlemler. Bu bireysel yapılabildiği gibi takım halinde de yapılabilir veya okullarda yapılan düzey belirleme sınavlarında öğrencilerin gösterdikleri performanslarda geliştirilmesi gereken alanların belirlenmesi ve eylem planları düzenlenmesi takımların yerine getirdikleri birer eylem araştırması örnekleridir.

Schoen ve Nolen 2004 yılında özel öğrenme güçlüğü çeken bir öğrencinin bilişsel davranışsal olarak beceri kazanmalarını sağlamak için bir eylem araştırması kapsamında incelemişlerdir. Öğrencinin problemi, sınıf içi gözlem yoluyla not edilmiş, ayrıca rehber öğretmeni, sınıf öğretmenleriyle ilgili daha detaylı bilgiler toplanmıştır. İlgili kaynakları tarayarak sosyal, bilişsel, davranışsal ve insanc kuramsal temellere dayalı uygulama planları belirlemişlerdir. Uygulamalar sırasında gözlemlere ve görüşmelere yer verilmiştir. 
Araştırmacılar uygulamalarını sistemli olarak gözden geçirdiklerinde ve analiz ettiklerinde kuramsal yaklaşıma dayalı uygulamanın öğrencinin olumlu davranışlarının artırılmasında olumlu etkilerinin olduğunu belirtmişlerdir.

Uzuner, İçden, Girgin, Beral ve Kıcaali-İftar 2005 yılında üç işitme engeli bulunan üniversite öğrencisine öykü yapısı alışkanlığını kazandırmak amacıyla bir eylem araştırması yapmışlardır. Yaklaşık iki buçuk ayda haftada üç saat çalışarak on beş uygulama gerçekleştirmişlerdir. Araştırma sonucunda, tüm öğrencilerin öyküleri anlama noktasında gelişme gösterdiğini ve öğrencilerin katılımı arttırdığı yönünde olmuştur.

Bir üniversitede öğretim üyesi olarak çalışan Marton, 2005 yılında sosyoekonomik olarak alt bölge sayılabilecek bir okulda, gönüllü olarak iki öğretmene kılavuzluk yapmıştır. Öğretmenleri sınıflarda gözleyerek çeşitli notlar ve video kayıtlar alarak gözlemlemiş ve geri dönütler vermiştir. Öğretmenlerin iletişimi noktasında ve sınıf kontrolü gibi alanlarda gördüğü eksiklikleri söylemiştir. Araştırmanın sonunda iki öğretmende bireysel olarak geliştiği yönünde olsa bile biri daha fazla direnç göstermiştir.

Michele ve Kretschmeri; 1996 yılında geleneksel gelişim modeline alternatif bir model olarak araştırmacı-öğretmen gelişim modeli üzerinde bir eylem araştırması modeli çalışmıştır. Bu çalışma eğitim sektöründe çeşitli görevlerde bulunan toplam 130 kişiden oluşmaktaydı. Bu araştırmada mesleki büyümenin nasıl gerçekleşebileceğini, Bireysel olarak gelişmeyi sağlayan ortamın nasıl oluşturulabileceği, öğretmenlerin kendilerini sadece kendi çalışmalarına göre değil, öğrencilerinin başarılarına göre de değerlendirmelerini nasıl geliştirebileceğini anlamak adına yapılan bir çalışmaydı. Bu araştırma sonunda, projenin birbiriyle bağlantılı iki alt boyutunun olduğu görülmüştür. İlk boyutu, öğretmenlerin kendilerinin geliştirmeleriydi; diğer boyutu ise katılımcılarının deneyimlerini paylaşması ve beyin fırtınası yapmalarıydı. Araştırma sonucunda, öğretmenlerin bir probleme bakış açılarının çeşitlendiğini ve öğretmenlerin akademik anlamda zenginleştiği yönündeydi.

Leff, Costigan ve Power, 2004 yılında, okul düzeyindeki saldırganlık davranışlarını azaltmak amacıyla bir eylem araştırması uygulamışlardır. Bu amaçla sosyal beceriler kazandırma ve işbirlikli oyunu temel alan çözüm önerileri sunmuşlardır. Bu öneriyle birlikte, okul müdürünün daveti üzerine şehir merkezinde bir oyun sahası programı uygulamışlardır. Oyun sahasında yeni düzenlemeler yapılmış ve öğretmenlere bu konuyla ilgili rehberlik edilmiştir. Araştırmacılar işbirliği yaparak okulun diğer elemanlarıyla birlikte 
etkileşimde bulunmuş ve farklı etnik gruptaki bireyleri önemsemişlerdir. Bu araştırma sonucunda işbirlikli oyununun saldırganlığı azalttığı ve öğrenciler arasında özsaygı becerilerinin geliştiği görülmüştür.

Sidekli, 2006 yılında ilkokul 4. Sınıf öğrencilerin okuma ve anlama güçlükleriyle ilgili bir eylem araştırması yapmıştır. Bu araştırma kapsamında Ankara ilinde ilkokul 4. Sınıf dört öğrenciyle birlikte gözlem yaparak öğrencilerin okuma esnasındaki yaptıkları hataları ve öğrencilerin değerlendirilmesi amaçlanmıştır. Öğrencilerin okuma ve anlama güçlük düzeyi belirlendikten sonra hatalarının nedenleri belirlenip öğrencilere geri dönütler verilmiştir. Araştırma sonucunda öğrencilerin sesli okuma, akıcı okuma ve okuduğunu anlama hatalarının sıklı̆̆ının azaldığı gözlemlenmiştir.

Tüzel, 2012 yılında ilköğretim ikinci kademe Türkçe dersinde medya okuryazarlığını geliştirme kapsamında bir eylem araştırması çalışmıştır. Bu araştırma kapsamında Türkçe derslerinin medya okuryazarlığına nasıl entegre edilebileceğini ve nasıl geliştirileceği üzerinedir. Öğrenci günlükleri, gözlem ve kayıt tutarak 19 öğrenciyi gözlemlemiştir. Öğrencilerin tutum ve davranışları arttığı sonucuna ulaşılmıştır.

Canbulut, Kula, Şahin, Tamtürk ve Eskicioğlu 2012 yılında yapmış oldukları sınıf öğretmeni adaylarının kütüphane kullanım düzeylerinin geliştirilmesinde kullanmış oldukları eylem araştırmasında 42 sınıf öğretmeni adayının kullanım düzeyleri belirlenmiş ve tutum ölçekleriyle birlikte geliştirmenin yollarını aramışlardır. Geliştirilen eylemler sonucunda katılımcılarda kütüphane kullanımına yönelik olumlu yönde gelişme sağlandığı görülmüştür.

\section{Sonuç ve Öneriler}

Eylem araştırması, öğretmenleri, eğitim niteliklerini geliştirecek araştırmalar yapmaya teşvik eder. Öğretmenin problemler karşısında çözüm önerileri geliştirmeyi ve öz değerlendirme becerilerini artırmayı hedefler. Bunu yaparken, öğretmenlerden, işbirlikçi yaklaşımı ve yansıtıcı düşünme becerilerini kullanmaları beklenir. Eylem araştırması sadece lokal sorunlarla değil, bazen bir kentin ya da bölgenin genel sorunlarını da ele alabilir. Bütün yaklaşımlarda ortak amaç problem çözmeyi sağlamaktır. Var olan sorunlar gözlem, kayıt, yansıtıcı yöntemlerle sunularak, paydaşlarla birlikte sorun çözmeyi amaçlar. Bu yönüyle eylem araştırmasında temel amaç eksikliklerin giderilmesini ya da var olan uygulamaların daha da geliştirilmesidir. Diğer yandan 
öğretmenin kendini tanımasını ve uygulamalrına eleştirel açıdan bakması sağlanmış olur. Ancak özellikle toplumumuzda eylem araştırması ile ilgili bilgi ve farkındalığın eksik olması, yöntemin ana sinırlılığını oluşturmaktadır. Dolayısıyla okullarda eylem araştırmlarının daha yaygın kullanılabilmesi için aşağıdaki önerilerde bulunulmuştur.

Sahada çalışan öğretmenlere, akademisyenler ya da konunun uzmanları tarafından eylem araştırmasının teorik ve uygulama boyutuyla ilgili seminerler verilmelidir. Lider konumundaki okul müdürlerinin eylem araştırması konusunda yeterli hale gelmeleri sağlanmalı ve öğretmenleri eylem araştırması kullanmaya teşvik eden bir okul kültürü geliştirmelerine olanak sağlanmalıdır. Öğretmenler ise basmakalıp yaklaşımlardan ziyade eğitim yöntemlerini geliştirme yönünde çaba harcamalı ve değişime açı olmalıdır. Böylece; hem okul yöneticileri hem de öğretmenler pasif uygulayıcılar olmaktan çkıp, bilimsel yaklaşıma dayalı çözüm odaklı uygulayıcılara dönüşmüş olurlar. 


\title{
EXTENDED ABSTRACT
}

\section{The Use and Importance of Action Research in Education}

\author{
* \\ Mahmut Karatay - Muhammed Taş \\ Munzur Universty-MONE
}

Action Research is a type of research that requires focus and analysis to improve a study qualitatively. This method, which has the opportunity to be applied in many subjects, is a method used in solving problems of individuals. Action research is important in terms of identifying the problem, providing application opportunities and offering solutions. It is a method that offers individuals a different perspective for solving the problem by creating awareness, together with processes such as defining the problem, collecting data about the problem and evaluating the data. Action research is a process of systematic inquiry that seeks to improve as rational and justice.

This research, designed and implemented by its practitioners, offers new opportunities for better teaching and evaluation, especially for teachers. In this context, action research is used as "program development", "professional development", "system planning", restructuring "and an" evaluation "tool. Action research encourages teachers to conduct research that will improve their educational qualifications. It aims to develop solutions for the teacher's problems and to increase their self-evaluation skills. While doing this, teachers are expected to use the collaborative approach and reflective thinking skills. The action research, which is one of the scientific research methods that are frequently used in the field of education, is accepted as a general qualitative research that the participation is preliminary, but it is seen that quantitative research methods and techniques are also used. To teach solutions across a problem that also affects teachers will be expected to further develop itself. It is not intended individually as well as problem-solving; Sometimes these problems at the school level, sometimes focusing on problems at a regional level. Common purpose is to solve problems at all. There are problems with the observation, recording, it aims to solve problems together with stakeholders presented with 
reflective method. Which lack or have been fixed to the intended further development. Teacher's self-knowledge and to look critically at an angle is provided. The action research, designed and implemented by practitioners, offers new opportunities, especially for teachers to solve problems and reflect on it in class, using different assessment techniques to improve and improve their work.

This study also discusses the historical development, purpose and features of the action research as a research method, its steps, data collection methods and techniques, its benefits, its use in teaching and examples. This research, which is a phenomenological study, includes creating a compact information source about the subject of action research and examples of the application of action research in the field of education. As a result, action research can be applied in schools at all levels of education. It offers teachers and students the opportunity to look from different perspectives and improves the teaching method. Teachers and students have the opportunity to use different methods to make applications in the classroom or school. Thus, the teacher's self-development will be reflected in the learning of the students. The teacher will empower himself in this regard and will be able to be aware of his own strengths and weaknesses. The applicability of action research, especially in schools, is important because it improves teachers' problem-solving skills on a topic that is, it has a significant effect on teachers' reflective thinking skills. This will help teachers to do their work and operations better. On the other hand, this method has some limitations both theoretically and practically. Both researchers and practitioners are responsibilities such as openness to change, giving theoretical information, being solution-oriented and so on. Therefore, teachers' problem-solving skills can be improved.

Studies have shown that the use of action research by teachers in the school environment, has been contributing to the administrative development of school life, ensure the personal professional development of teachers when it is desired to use scientific methods instead of traditional methods, determine and develop the level of understanding of the student when it is desired to develop different ideas about a subject.

The following suggestions have been made in order for action research to be used more widely in schools. Teachers working in the field should be given seminars on the theoretical and practical aspects of action 
research by academics or experts. Leading school principals should be made competent in action research, and they should be enabled to develop a school culture that encourages teachers to use action research. Teachers, on the other hand, should strive to improve education methods rather than stereotypical approaches and should be open to change. Thus; both school administrators and teachers cease to be passive practitioners and turn into solution-oriented practitioners based on a scientific approach.

\section{Kaynakça / References}

Aksoy, N. (2003). Action research: A method for improving and changing educational practices. Educational Administration in Theory and Practice.

Aydın, İ. (2016). Öğretimde denetim: Durum saptama, değerlendirme ve geliştirme. Ankara: PegemA Yayıncilik.

Beyhan, A. (2013). Eğitim örgütlerinde eylem araştırması. Bilgisayar ve Ĕgitim Araştırmalarn Dergisi, 1(1), 65-89.

Biesta, G. J. J., Stengel, B. S. (2016). Thinking philosophically about teaching. In Gitmoer, D. H., Bell, C. A. (Eds.), Handbook of research on teaching (5th ed., s. 7-66). Washington, DC: American Educational Research Association.)

Burns, A. (2019). Action research: Developments, characteristics, and future directions. In J. Schwieter \& A. Benati (Eds.), The Cambridge Handbook of Language Learning (Cambridge Handbooks in Language and Linguistics, içinde (s. 166-185). Cambridge: Cambridge University Press. doi:10.1017/9781108333603.008).

Costello, P.J.M. (2007). Action research. Continuum Books: London.

Eilks, I. (2018) Action research in science education: A twenty-years personal perspective. Action Research and Innovation in Science Education, 1(1), 3-14

Ekiz, D. (2009). Bilimsel araştırma yöntemleri. Ankara: Anı yayıncllk

Elliot, J. (1991). Action research for educational change. Open University Press. Buckingham

Farley-Ripple, E., May, H., Karpyn, A., Tilley, K., McDonough, K. (2018). Rethinking connections between research and practice in education: A conceptual framework. Educational Researcher, 47, 235-245.

Ferrance, E. (2000). Action research: Themes in education. USA: Northeast and Islands Regional Educational Laboratory at Brown University.

Glickman, C. D. (2002). Leadership for learning: How to help teachers succeed. ASCD.

Glanz, J. (1999). A Primer on Antian Research for the School Administratars. The Clearing House, May-June, 301 -304. 
Gottlieb, D. (2014). Education reform and the concept of good teaching. New York, NY: Routledge.

Hendricks, C. (2016). Improving schools through action resarch. ABD: Pearson EDUC.

Hopkins, D. (1993). A teacher's guide to classroom research (2nd edition). Buckingham \& Philadelphia: Open University Press.

Johnson, A. P. (2014). Eylem araştırması el kitabı Çeviri Ed. Uzuner Y, Anay M.. Ankara: Anı Yayıncilı.

Kemmis, S. (1988). Action research. in J. P. Keeves (Ed.). Educational Research, Methodology, and Measurement: An International Handbook (p.177-190). Oxford: Pergamon,

Kinchole, J. L. (1993). Teachers as reseachers: Qualitative Inquiry as a Path to Empowerement. The Falmer Press.

Kuzu, A. (2009). Öğretmen yetiştirme ve mesleki gelişimde eylem araştırması. Uluslararası Sosyal Araştırmalar Dergisi, 2(6), 425-433.

Köklü, N. (2001). Eğitim eylem araştırması -öğretmen araştırması. Ankara Üniversitesi Eğitim Bilimleri Dergisi, 34(1-2), 35-43.

Leff, S. S., Costigan, T., ve Power, T. J. (2004). Using participatory research to develop a playground-based prevention program. Journal of School Psychology, 42(1), 3-21.

Lesha, J. (2014). Action research in education. European Scientific Journal, ESJ, 10(13). https://doi.org/10.19044/esj.2014.v10n13p\%p

Lewin, K. (1946) Action research and minority problems. Journal of Social Issues, 2, 3446.

Manfra, M. M. (2019). Action Research and systematic, intentional change in teaching practice. Review of Research in Education,43(1), 163196. https://doi.org/10.3102/0091732X18821132

Masters, Janet. (1995). The history of action research. In I. Hughes (Ed) Action research electronic reader, The University Of Sydney, On-Line 11.10.2018 tarihinde .Http://Www.Behs.Cchs.Usyd.Edu.Au/Arow/Reader/Rmasters.Htm adresinden erişilmiştir.

McNiff, Jean. (1988). Action research. Principles and Practice, Routledge.

Michele, G., ve Kretschmer, R. E. (1996). Teachers as researchers: Supporting professional development. the Volta Review, 98(3), 81-103

Mills, G. E. (2003). Action research: A Guide for the Teacher Researcher. (2nd ed.). Upper Saddle River, NJ: Merrill Prentice Hall.

Mills, G. (2017). Action research: A guide for the teacher researcher (6th ed.). NY:

Pearson Education). 
Morton, M. K. (2005). Practicing praxis: Mentoring teachers in a low-income school through collaborative action research and transformative pedagogy. Mentoring and Tutoring, 13(1), 53-72.

Nasrollahi, M.A., Krish,P., Noor,N.M. (2012). Action research in language learning. Procedia - Social and Behavioral Sciences, 47, 1874-1879.

O'Brien, R. (1998). An Overview of the methodological approach of action research. R. Richardson (Ed.). Theory and Practice of Action Research. 11.10.2018 tarihinde http://www.web.net/ robrien/papers/arfinal.html adresinden erişilmiştir.

Reason, P. (2001). Learning and change through action research. (Ed). J. Henry. Creative Management. London: Sage. Publications

Sagor, R. (2003). Guiding school improvement with action research. 11.10.2018 tarihinde http://www.ascd.or.vreadingroom/bO.JkslsagorOObook.htm adresinden erişilmiştir.

Schoen, S. F., ve Nolen, J. (2004). Action research: Decreasing acting-out behavior and increasing learning. Teaching Exceptional Children, 37(1), 26-29.

Sidekli, A. (2014). Eylem araştırması: Illköğretim dördüncü sınıf öğrencilerinin okuma ve anlama güçlüklerinin giderilmesi. Türklük Bilimi Araştırmaları, (27),563580.

Tezcan, Ö., Ada, S., ve Baysal, N. (2016). Eğitim alanında eylem araştırmaları. Kocaeli Üniversitesi Sosyal Bilimler Dergisi. KOSBED, 32, 133-148

Tüzel, S. (2012). İköğretim ikinci kademe türkçe derslerinde medya okuryazarlı̆̆ı eğitimi: bir eylem araştırması. (Yayınlanmamış Doktora Tezi), Çanakkale Onsekiz Mart Üniversitesi Eğitim Bilimleri Enstitüsü, Çanakkale.

Uzuner Y., İçden, G., Girgin, Ü., Beral, A., ve Kırcaali-İftar, G. (2005) An examination of impacts of text related questions on story grammar acquisition of three Turkish youths with hearing loss. International Journal of Special Education, 20(2), 111-121

Yıldırım, A. ve Şimşek, H. (2016). Sosyal bilimlerde nitel araştırma yöntemleri (10. Baskı). Ankara: Seçkin Yayıncllk

Yiğit, C. (2016). Öğretmenlerin mesleki gelişiminde eylem araştırmasmmn kurkpatric program değerlendirme modeline göre incelenmesi. (Doktora Tezi), Gaziantep Üniversitesi, Eğitim Bilimleri Enstitüsü, Gaziantep.

Wadsworth, Y. (1998). What is participatory action research? Action Research International, $\quad$ Paper $2 . \quad$ http://www.scu.edu.au/schools/gcm/ar/ari/pywadsworth98.html 
Kaynakça Bilgisi / Citation Information

Karatay, M. ve Taş, M. (2021). Eylem araştırması'nın eğitim alanında kullanımı ve önemi. OPUS-Uluslararası Toplum Araştırmaları Dergisi, 17(38), 5545-5568. DOI: 10.26466/opus.736788 